\title{
Long-term safety and tolerability of atabecestat (JNJ-54861911), an oral BACE1 inhibitor, in early Alzheimer's disease spectrum patients: a randomized, double- blind, placebo-controlled study and a two- period extension study
}

Gerald Novak ${ }^{1 *}$, Johannes Rolf Streffer ${ }^{2,3,4}$, Maarten Timmers ${ }^{2,3}$, David Henley ${ }^{1}$, H. Robert Brashear ${ }^{1}$, Jennifer Bogert ${ }^{5}$, Alberto Russu², Luc Janssens², Ina Tesseur ${ }^{2,4}$, Luc Tritsmans², Luc Van Nueten ${ }^{2}$ and Sebastiaan Engelborghs $s^{3,6}$

\begin{abstract}
Background: Atabecestat, a potent brain-penetrable inhibitor of BACE1 activity that reduces CSF amyloid beta (A $\beta$ ), was developed for oral treatment for Alzheimer's disease (AD).

The long-term safety and effect of atabecestat on cognitive performance in participants with predementia AD in two phase 2 studies were assessed.

Methods: In the placebo-controlled double-blind parent ALZ2002 study, participants aged 50 to 85 years were randomized (1:1:1) to placebo or atabecestat 10 or $50 \mathrm{mg}$ once daily (later reduced to 5 and $25 \mathrm{mg}$ ) for 6 months. Participants entered ALZ2004, a 12-month treatment extension with placebo or atabecestat 10 or 25 mg, followed by an open-label phase. Safety, changes in CSF biomarker levels, brain volume, and effects on cognitive performance were assessed.

Results: Of 114 participants randomized in ALZ2002, 99 (87\%) completed, 90 entered the ALZ2004 double-blind phase, and 77 progressed to the open-label phase. CSF A fragments and SAPP $\beta$ were reduced dose-proportionately. Decreases in whole brain and hippocampal volumes were greater in participants with mild cognitive impairment (MCI) due to AD than in preclinical AD, but were not affected by treatment. In ALZ2004, change from baseline in RBANS trended toward worse scores for atabecestat versus placebo. Elevated liver enzyme adverse events reported in 12 participants on atabecestat resulted in dosage modification and increased frequency of safety monitoring. Treatment discontinuation normalized ALT or AST in all except one with pretreatment elevation, which remained mildly elevated. No case met ALT/AST $>3 \times$ ULN and total bilirubin > 2x ULN (Hy's law).

(Continued on next page)
\end{abstract}

\footnotetext{
* Correspondence: gnovak1@its.jnj.com

'Janssen Research and Development LLC, 1125 Trenton-Harbourton Rd, Titusville, NJ 08560, USA

Full list of author information is available at the end of the article
}

C C The Author(s). 2020 Open Access This article is licensed under a Creative Commons Attribution 4.0 International License, which permits use, sharing, adaptation, distribution and reproduction in any medium or format, as long as you give appropriate credit to the original author(s) and the source, provide a link to the Creative Commons licence, and indicate if changes were made. The images or other third party material in this article are included in the article's Creative Commons licence, unless indicated otherwise in a credit line to the material. If material is not included in the article's Creative Commons licence and your intended use is not permitted by statutory regulation or exceeds the permitted use, you will need to obtain permission directly from the copyright holder. To view a copy of this licence, visit http://creativecommons.org/licenses/by/4.0/. The Creative Commons Public Domain Dedication waiver (http://creativecommons.org/publicdomain/zero/1.0/) applies to the data made available in this article, unless otherwise stated in a credit line to the data. 
(Continued from previous page)

Conclusion: Atabecestat was associated with trend toward declines in cognition, and elevation of liver enzymes.

Trial registration: ALZ2002: ClinicalTrials.gov, NCT02260674, registered October 9, 2014; ALZ2004: ClinicalTrials.gov, NCT02406027, registered April 1, 2015.

Keywords: Atabecestat, BACE1 inhibitor, Alzheimer's disease, Predementia, Amyloid, A $\beta$, Cognition, Liver enzyme elevation

\section{Background}

Cleavage of the amyloid precursor protein (APP) by $\beta$ secretase1 (BACE1) is the first and rate limiting step in the production of amyloid beta $(A \beta)$, the main constituent of amyloid plaques, a hallmark pathological feature of Alzheimer's disease (AD). Subsequent cleavage by $\gamma$ secretase results in the production of $A \beta_{1-42}$, which has a high tendency to aggregate, as well as other $A \beta$ fragments of shorter length, of which $A \beta_{1-40}$ is the most prevalent. These $\mathrm{A} \beta$ forms can also aggregate to form oligomers and fibrils $[1,2]$. Thus, inhibitors of BACE1 prevent the formation of $A \beta_{1-42}$ as well as $A \beta_{1-40}, A \beta_{1-}$ 38, and $\mathrm{A} \beta_{1-37}$ and are potentially disease-modifying therapeutic agents in the treatment of AD.

Supporting this mechanism is the observed correlation between the catalytic efficiency of BACE1 for its substrate APP and the occurrence of AD. The Swedish APP mutant (KM670/671NL), a more efficient substrate for BACE1 $(10 \times)$, causes a rare familial form of AD that is inherited in the dominant Mendelian fashion. On the other end of the spectrum is an allelic variant of APP (A673T), a less efficient substrate for BACE1 $(0.5 \times)$, which is protective against sporadic AD [3].

Atabecestat (formerly JNJ-54861911) is a potent brainpenetrable BACE1 inhibitor developed by Janssen Research \& Development in collaboration with Shionogi as an oral treatment of $\mathrm{AD}$, with reduction of CSF $\mathrm{A} \beta$ as its primary mode of action [4]. In phase 1 studies in elderly Caucasian and Japanese participants with preclinical AD and mild cognitive impairment $(\mathrm{MCI})$ due to $\mathrm{AD}$, treatment with atabecestat at $10 \mathrm{mg}$ and $50 \mathrm{mg}$ for 4 weeks significantly reduced from baseline CSF levels of $\mathrm{A} \beta_{1-40}$ by $67 \%$ and $90 \%$, respectively, as compared to placebo and was well tolerated [5]. Similar reductions were observed in all other $A \beta$ fragments. The observed steadystate CSF $A \beta_{1-40}$ reductions from baseline were within the $95 \%$ confidence interval predicted by pharmacokinetic/pharmacodynamic modeling from a multiple ascending dose phase 1 study in healthy population (5 to $50 \mathrm{mg}$ once daily for 14 days).

We report two phase 2 studies (ALZ2002 and ALZ2004) whose primary objectives were to assess the long-term safety and tolerability of atabecestat in patients with early $\mathrm{AD}$ (predementia AD; encompasses preclinical AD to mild cognitive impairment [MCI]). The parent study, ALZ2002, was a randomized double-blind, placebo-controlled study designed to investigate the safety profile of atabecestat during 6 months of treatment. This was followed by the longer term ALZ2004 extension study that consisted of 2 sequential treatment phases: a 12-month double-blind placebocontrolled treatment phase of atabecestat, followed by an open-label (OL) active treatment phase.

In the ALZ2004 extension study, the effects of atabecestat relative to placebo over time on cognition, performance of everyday functions, and brain volume as assessed by MRI were evaluated as secondary endpoints. In both studies, secondary and exploratory endpoints included the effect of treatment on the change in CSF levels of downstream biomarkers, including $A \beta$ fragments $\left(A \beta_{1-37}, A \beta_{1-38}, A \beta_{1-40}, A \beta_{1-42}\right)$, soluble APP (sAPP) fragments (sAPP $\alpha, \operatorname{sAPP} \beta$, and total sAPP), total tau (t-tau), and phosphorylated tau ( $\mathrm{p}$ - $\left.\operatorname{tau}_{181}\right)$.

\section{Methods}

\section{Study population and selection criteria}

The ALZ2002 parent study (NCT02260674) and the ALZ2004 extension study (NCT02406027) were multicenter, double-blind, placebo-controlled, randomized, multiple dose safety and tolerability studies in patients in the early (predementia) AD spectrum conducted in sites in Belgium, France, Germany, Netherlands, Sweden, and Spain from February 2016 to June 2018.

The parent ALZ2002 study population consisted of men and women who entered the study either directly as new patients or after completing 4 weeks of double-blind treatment in study ALZ1005, a phase 1 placebo-controlled study in participants meeting the same inclusion criteria [5]. The ALZ2002 patient population included asymptomatic individuals diagnosed as preclinical AD (aged 65 to 85 years) who were cognitively and functionally unimpaired with a Clinical Dementia Rating (CDR) global scale score of 0 and those diagnosed with MCI due to AD (aged 50 to 85 years) who had mild cognitive impairment but were functionally unimpaired with CDR global score of 0.5. Those with CDR global scores higher than 0.5 were excluded. Participants were considered otherwise healthy for their age with a body mass index (BMI) between 18 and $35 \mathrm{~kg} / \mathrm{m}^{2}$.

Participants were excluded if they had any of the following: a diagnosis of dementia, or another degenerative brain disorder that can cause dementia; evidence of familial autosomal dominant $\mathrm{AD}$, or any brain disease 
other than potential very early signs of $\mathrm{AD}$; any other abnormality that could explain cognitive deficit such as vitamin $B_{12}$ or folic acid deficiency, vascular encephalopathy, or strokes including lacunae; any finding on magnetic resonance imaging (MRI) of brain disease, other than mild hippocampal atrophy or typical age-related mild white matter hyperintensity; a Rosen modified Hachinski ischemic scale score of $>4$; any contraindications for MRI; chromosome 21 trisomy (Down syndrome); major depression, as defined by the most current Diagnostic and Statistical Manual of Mental Disorders (DSM) criteria; or liver or renal insufficiency, or other clinically significant medical disorders. Treatment of stable medical conditions including the use of cognitive enhancers (e.g., cholinesterase inhibitors or memantine) was allowed, if started $\geq 30$ days prior to the first study dose.

All participants had evidence of amyloid pathology at screening based on low CSF $A \beta_{1-42}$ level having a concentration below the laboratory-specific cut-off value of $600 \mathrm{ng} / \mathrm{L}$, analyzed in one central laboratory using INNOTEST $^{\bullet} \beta$-AMYLOID ${ }_{1-42}$ assay (Fujirebio, Ghent, Belgium) [6, 7] or by a positive amyloid positron emission tomography (PET) scan at screening based on visual inspection of PET imaging scan performed at a core imaging laboratory.

\section{Study design}

The ALZ2002 parent study included a 90-day screening period, followed by 6 months of double-blind treatment randomized 1:1:1 to placebo or atabecestat $10 \mathrm{mg}$ or 50 $\mathrm{mg}$ once daily (given as 2 identical tablets of placebo, 5 $\mathrm{mg}$, or $25 \mathrm{mg}$ ). Individuals that had completed the ALZ1005 study continued the same blinded treatment to which they had originally been randomized. After completion of month 6 of the ALZ2002 study, participants had the option to enroll in the ALZ2004 extension study; otherwise, they returned for a follow-up visit 7 to 28 days after last dose. Those who had progressed to dementia (CDR global score $\geq 1$ ) in ALZ2002 were not eligible for enrollment in the ALZ2004; in case of progression to a dementia state during the course of ALZ2004, a renewed consent to remain in the study was obtained from the participant or a representative, provided they chose to continue and the investigator judged potential benefits of treatment outweighed foreseeable risks for that participant.

ALZ2004 consisted of 2 sequential treatment periods. In the initial 12-month double-blind phase, participants who were originally assigned to $50 \mathrm{mg}$ atabecestat once daily in ALZ2002 were reduced to $25 \mathrm{mg}$, while those receiving $10 \mathrm{mg}$ atabecestat or placebo continued their previously assigned treatment. This was followed by an open-label phase, where participants on $25 \mathrm{mg}$ continued to receive that dosage, those on atabecestat $10 \mathrm{mg}$ were decreased to $5 \mathrm{mg}$, and those on placebo were randomized with equal probability to 5 or $25 \mathrm{mg}$. The rationale for the 5-mg dosage was to identify a dose that may not require monitoring of hepatic enzymes, while still providing adequate target CSF $A \beta_{1-40}$ reduction of $52 \%$ (95\% CI 27-72\%) [4]. The sequence of dosing in all phases of ALZ2002 and ALZ2004 is summarized graphically in Fig. 1.

Approximately 3 months after the completion of enrollment in study ALZ2002, the design of the study was substantially amended due to observations of elevated liver enzymes in some patients. Participants who had not yet completed ALZ2002 had a reduction in dosage of blinded study drug from 2 to 1 tablet per day (thus, from $50 \mathrm{mg}, 10 \mathrm{mg}$, or placebo to $25 \mathrm{mg}, 5 \mathrm{mg}$, or placebo, respectively). More frequent monitoring of serum chemistry and rules for stopping treatment were implemented for alanine aminotransferase (ALT) or aspartate aminotransferase (AST) $>8 \times$ upper limit of normal (ULN), ALT or AST $>5 \times$ ULN for more than 2 weeks, ALT or AST $>3 \times$ ULN and total bilirubin $>2 \times$ ULN or international normalized ratio $>1.5$, or ALT or AST $>3 \times$ ULN with the appearance of fatigue, nausea, vomiting, right upper quadrant pain or tenderness, fever, rash, and/or eosinophilia (>5\%) [8]. Because of the continued high frequency of elevated liver enzymes observed in this study as well as in a separate parallel running phase $2 \mathrm{~b} / 3$ trial of atabecestat in preclinical AD (the EARLY study, ALZ2003, NCT02569398), the sponsor judged that the risks did not merit continued treatment and dosing in all atabecestat trials was terminated in May 2018.

\section{Assessments \\ Cognition}

Cognitive assessments performed prior to the initiation of treatment in ALZ2002 included the CDR-Sum of Boxes (CDR-SB), from which a global score was calculated to establish eligibility, the Mini-Mental State Examination (MMSE), the Repeatable Battery for the Assessment of Neuropsychological Status (RBANS) (performed twice, with the second session serving as the baseline measurement), and the California Verbal Learning Test-second edition [CVLT-II]) performed prior to dosing on day 1 (see Supplementary material for descriptions). The CDR-SB, MMSE, and RBANS were repeated at the 6-month visit in ALZ2002. Those participants entering ALZ2004 then had the CDR-SB and MMSE repeated at week 52 in the double-blind treatment period and thereafter every 48 weeks in the open-label period. The RBANS was repeated at weeks 24 and 52 in the double-blind period and thereafter every 


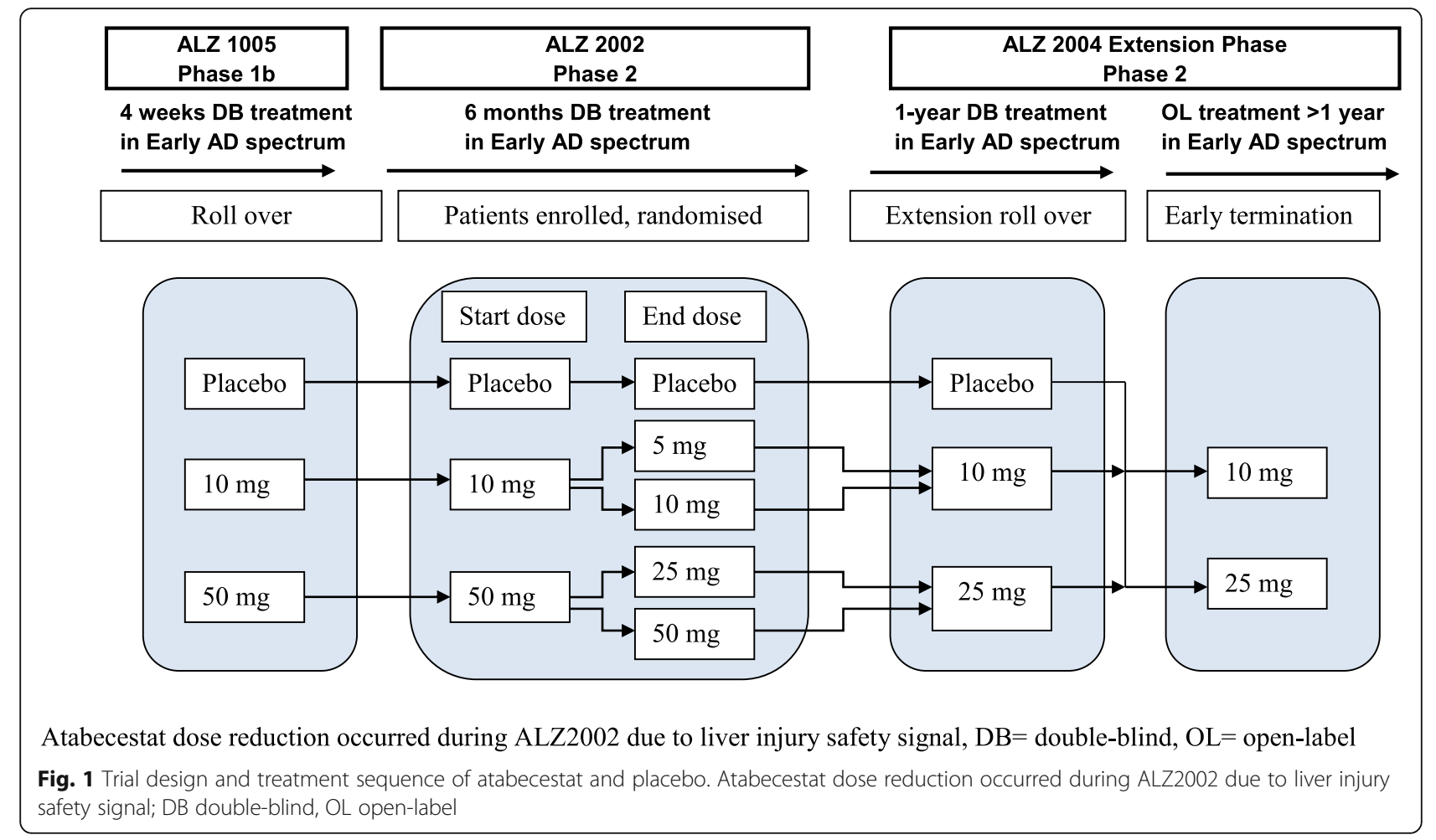

24 weeks in the open-label period. The CVLT was repeated only at week 12 in the double-blind period. A patient-reported outcome, the Cognitive Function Index (CFI), was first administered on day 1 of ALZ2004 and was repeated at weeks 24 and 52 in the double-blind period and thereafter every 24 weeks in the open-label period.

\section{Biomarkers}

The pharmacodynamic effects of atabecestat on BACE1 activity were evaluated through effects relative to baseline on CSF concentrations of $A \beta$ fragments $\left(A \beta_{1-37}\right.$, $A \beta_{1-38}, A \beta_{1-40}$, and $A \beta_{1-42}$ ), with $A \beta_{1-40}$ being the most abundant and primary determinant of atabecestat activity. A qualified Janssen multiplex immunoassay based on Meso Scale Discovery (MSD) (Gaithersburg, MD, USA) electrochemiluminescence (ECL) detection technology was utilized for simultaneous detection of all $4 \mathrm{~A} \beta$ fragments in CSF and plasma $[9,10]$. In addition, exploratory measurements of CSF levels of sAPP fragments (sAPP $\alpha$, sAPP $\beta$ ) and other CSF biomarkers (i.e., CSF ptau and $\mathrm{t}$-tau) were performed by a central laboratory as previously described by Timmers et al. [4]. Potential atabecestat treatment effects on brain volume were assessed with MRI at baseline and month 6 in ALZ2002 and at double-blind period weeks 24 and 52 and thereafter every 48 weeks in ALZ2004, using the boundary shift integral method [11].

\section{Pharmacokinetics}

Sparse plasma pharmacokinetic (PK) samples were collected at pre-dose of baseline and days 28, 56, 84, 112, 140, and 168 (month 6). As some participants in ALZ2002 entered the study from ALZ1005, data from the 2 studies were pooled in order to perform a combined population PK analysis. PK samples from study ALZ2004 were not included in the analysis. The PK dataset contained a total of 702 PK samples from 90 individuals. Population PK modeling was performed on the PK dataset in order to derive individual estimates of exposure (area under the plasma concentration-time curve at steady state, $\mathrm{AUC}_{0-24 \mathrm{~h}}$, calculated as dose/(CL/F) where CL/F is the individual estimate of oral clearance) for the participants included in the PK dataset.

\section{Safety assessments}

All participants who received study treatment were included in the safety analysis population. Safety and tolerability were assessed by recording adverse events (AEs) and clinically significant abnormalities on clinical laboratory tests (hematology, biochemistry, including liver function tests), 12-lead electrocardiogram, vital signs, and abnormalities on physical or neurological exams, and potential dermatologic and ophthalmologic abnormalities (e.g., melanin deposition changes and retinal abnormalities). In order to monitor for potential changes in melanin deposition 
and retinal abnormalities [12], all included participants had a baseline ophthalmological examination, optical coherence tomography, and examination of the skin by a dermatologist. These examinations were repeated in case of abnormality at baseline or new visual signs or symptoms.

MRI was used to monitor for amyloid-related imaging abnormalities (ARIA) with edema or effusion (ARIA-E) or with hemosiderin (ARIA-H), as previously reported with several anti-amyloid monoclonal antibodies [13]. AEs were coded using Medical Dictionary for Regulatory Activities (MedDRA) version 19.1 or later. Possible effects on anxiety or mood were assessed by the Geriatric Depression Scale, the State-Trait Anxiety Inventory, and the Columbia Suicide Severity Rating Scale (C-SSRS), performed at screening and on scheduled visits thereafter.

\section{Statistical analysis}

No formal hypothesis testing was planned, and sample sizes for the studies were not based on formal statistical testing. However, using assumptions that an $\mathrm{AE}$ occurred at the rates of $1 \%, 5 \%$, or $10 \%$ in a single treatment group, then the chances of observing such an $\mathrm{AE}$ among 30 participants receiving that treatment was estimated to be $26 \%, 79 \%$, or $96 \%$, respectively. Thus, planned enrollment of 100 participants (approximately 33 per group) was considered sufficient for clinical judgment of safety and tolerability of atabecestat.

Percent change from baseline in CSF concentration of each of the $A \beta$ fragments $\left(A \beta_{1-37}, A \beta_{1-38}, A \beta_{1-40}\right.$, and $\mathrm{A} \beta_{1-42}$ ), of sAPP $\alpha$ and sAPP $\beta$, and of p-tau and $t$-tau was summarized by box and whisker plots separately by treatment group and by baseline CDR status (i.e., preclinical $\mathrm{AD}, \mathrm{MCI}$ due to $\mathrm{AD}$ ) for month 6 in ALZ2002 and week 52 in the double-blind period of ALZ2004.

Change in cognition at week 52 of the double-blind period in ALZ2004 relative to baseline in ALZ2002 was analyzed with an ANCOVA model which included the treatment group, actual baseline CDR status, and baseline score as a covariate. For non-biomarker assessments, baseline for the ALZ2004 double-blind period safety analysis set was the value taken prior to the first study drug dose in the ALZ2002. For the open-label period in ALZ2004, baseline was the last value taken before the first dose in that period.

\section{Results}

Demographics, baseline characteristics, and disposition A total of 114 participants were enrolled in the ALZ2002 parent study, including 27 who entered from ALZ1005 (placebo, $n=11$; atabecestat $10 \mathrm{mg}, n=8$; and atabecestat $50 \mathrm{mg}, n=8$ ). Ninety participants were classified with $\mathrm{MCI}$ due to $\mathrm{AD}$ and 24 with preclinical $\mathrm{AD}$. Participant demographics, apolipoprotein E $\varepsilon 4$ ( $A P O E$ $\varepsilon 4)$ carrier status, and global CDR score are summarized in Table 1 by treatment group at the start of the study. These baseline characteristics were generally well balanced across treatment groups. Nearly all participants were Caucasians. APOE genotype was available for $69 \%$ of individuals: majorities were carriers of the $\varepsilon 4$ allele. Baseline/day 1 pre-dose scores for clinical scales and cognitive assessments by treatment groups at start and by the CDR diagnostic group are shown in Table 2 . In general, scores were comparable across treatment groups; however, patients classified with MCI due to $\mathrm{AD}$ showed more pronounced impairment on the MMSE,

Table 1 Baseline demographic characteristics of patients enrolled in the ALZ2002 (safety set)

\begin{tabular}{|c|c|c|c|c|}
\hline \multirow[t]{2}{*}{ Baseline characteristics } & \multicolumn{4}{|c|}{ Treatment group at start ALZ2002 } \\
\hline & Placebo & $10 \mathrm{mg}$ & $50 \mathrm{mg}$ & Total \\
\hline$N$ & 39 & 37 & 38 & 114 \\
\hline Sex, men, $n$ (\%) & $16(41.0)$ & $18(48.6)$ & $20(52.6)$ & $54(47.4)$ \\
\hline \multicolumn{5}{|l|}{ Age, years } \\
\hline Mean (SD) & $70.3(5.38)$ & $70.9(6.58)$ & $68.1(8.55)$ & $69.8(6.99)$ \\
\hline Range & $59 ; 80$ & $52 ; 81$ & $50 ; 82$ & $50 ; 82$ \\
\hline \multicolumn{5}{|l|}{ Race } \\
\hline White, $n$ (\%) & $37(94.9)$ & $36(97.3 \%)$ & $38(100.0)$ & $111(97.4)$ \\
\hline Other, $n(\%)$ & $2(5.1)$ & $1(2.7)$ & $0(0.0)$ & $3(2.6)$ \\
\hline$A P O E$ \&4 carrier status known, $n$ & 27 & 30 & 22 & 79 \\
\hline Yes, $n(\%)$ & $17(63.0)$ & $18(60.0)$ & $10(45.5)$ & $45(57.0)$ \\
\hline No, $n(\%)$ & $10(37.0)$ & $12(40.0)$ & $11(50.0)$ & $33(41.8)$ \\
\hline Preclinical $A D, C D R=0, n(\%)$ & $7(17.9)$ & $8(21.6)$ & $9(23.7)$ & $24(21.1)$ \\
\hline $\mathrm{MCl}$ due to $\mathrm{AD}, \mathrm{CDR}=0.5, n(\%)$ & $32(82.1)$ & $29(78.4)$ & $29(76.3)$ & 90 (78.9) \\
\hline
\end{tabular}


Table 2 Baseline clinical and cognitive characteristics of patients in parent study ALZ2002 by treatment group at start and by their Clinical Dementia Rating classification (safety analysis set)

\begin{tabular}{|c|c|c|c|}
\hline \multirow{3}{*}{$\begin{array}{l}\text { Baseline characteristics } \\
\text { Clinical and Cognitive Scales }\end{array}$} & \multicolumn{3}{|c|}{ Treatment group at start } \\
\hline & \multirow{2}{*}{$\begin{array}{l}\text { Placebo } \\
(\boldsymbol{N}=39)\end{array}$} & \multicolumn{2}{|l|}{ Atabecestat } \\
\hline & & $10 \mathrm{mg}(\boldsymbol{N}=37)$ & $50 \mathrm{mg}(\boldsymbol{N}=38)$ \\
\hline $\mathrm{CDR}^{-\mathrm{SB}^{\dagger}}, N$ & 39 & 37 & 38 \\
\hline All mean (SD) & $1.5(1.25)$ & $1.6(1.24)$ & $1.6(1.09)$ \\
\hline Preclinical AD, $N$ & 7 & 8 & 9 \\
\hline Mean (SD) & $0.1(0.19)$ & $0.4(0.73)$ & $0.8(0.97)$ \\
\hline $\mathrm{MCl}$ due to $A D, N$ & 32 & 29 & 29 \\
\hline Mean (SD) & $1.8(1.16)$ & $1.9(1.16)$ & $1.8(1.04)$ \\
\hline CVLT-II, long-delay recall\|, $N$ & 36 & 36 & 37 \\
\hline All mean (SD) & $11.7(9.4)$ & $10.3(9.04)$ & $12.4(8.48)$ \\
\hline Preclinical AD, $N$ & 7 & 8 & 9 \\
\hline Mean (SD) & $19.7(7.67)$ & $15.8(12.29)$ & $20.7(8.14)$ \\
\hline $\mathrm{MCl}$ due to $\mathrm{AD}, N$ & 29 & 28 & 28 \\
\hline Mean (SD) & $9.7(8.46)$ & $8.8(7.45)$ & $9.8(6.80)$ \\
\hline MMSE subscale scores ${ }^{\ddagger}, N$ & 39 & 37 & 38 \\
\hline All mean (SD) & $26.3(2.90)$ & $24.9(4.14)$ & $26.2(2.47)$ \\
\hline Preclinical AD, $N$ & 7 & 8 & 9 \\
\hline Mean (SD) & $29.0(1.15)$ & $27.8(2.55)$ & $27.8(2.64)$ \\
\hline $\mathrm{MCl}$ due to $\mathrm{AD}, N$ & 32 & 29 & 29 \\
\hline Mean (SD) & $25.8(2.84)$ & $24.1(4.18)$ & $25.7(2.24)$ \\
\hline RBANS-total scale score", $N$ & 39 & 37 & 38 \\
\hline All, mean (SD) & $80.2(17.10)$ & $72.4(21.99)$ & $80.1(17.44)$ \\
\hline Preclinical AD, $N$ & 7 & 8 & 9 \\
\hline Mean (SD) & $99.7(14.68)$ & $91.4(23.89)$ & $92.9(17.49)$ \\
\hline $\mathrm{MCl}$ due to $\mathrm{AD}, N$ & 32 & 29 & 29 \\
\hline Mean (SD) & $75.9(14.55)$ & $67.2(18.66)$ & $76.2(15.68)$ \\
\hline
\end{tabular}

${ }^{\dagger}$ The Clinical Dementia Rating-Sum of Boxes with scores ranging from 0 to 18 with higher scores indicating more pronounced impairment

"The California Verbal Learning Test-second edition long-delay recall subtest is derived as the sum of free recall and cued recall 20 min after the initial presentation of a word list. The lower the score, the more pronounced the impairment

${ }^{\ddagger}$ The Mini-Mental State Examination is a questionnaire that rates participants on orientation (total score, 10), registration (total score, 3 ), attention, calculation (total score, 5), recall (total score, 3), and language (total score, 9). The maximum score is 30 . The lower the score, the more pronounced the impairment "The Repeatable Battery for the Assessment of Neuropsychological Status subsets included attention index, language index, visuospatial/constructional index, immediate memory index, and delayed memory index. The lower the score, the more pronounced the impairment

CDR-SB, RBANS, and CVLT-II, compared to those with preclinical AD.

By the time the dosage of blinded study drug was reduced due to elevated hepatic enzymes, all participants had been enrolled in ALZ2002 and had completed at least 3 months of treatment. The resulting treatment exposures over 6 months (mean daily dose) were relatively similar between those that underwent dosage reduction and those that completed month 6 on the originally assigned dosage (9 mg vs $10 \mathrm{mg}$ for $5 \mathrm{mg}$ [dose-reduced] and $10 \mathrm{mg}$ [completed on original dose], and $40 \mathrm{mg}$ vs $50 \mathrm{mg}$ for $25 \mathrm{mg}$ [dose-reduced] and $50 \mathrm{mg}$ [completed on original dose], respectively).
Participant disposition and study completion for the ALZ2002 study are shown in Fig. 2. Of the 114 participants enrolled, 99 (87\%) completed 6 months of double-blind treatment in ALZ2002. The most common reason for discontinuation of the study drug was an $\mathrm{AE}$ in 9 (7.9\%) participants.

In ALZ2004, 90 participants enrolled into the double-blind period of the study; 77 (85.6\%) of these completed the double-blind period and progressed to the open-label period (Fig. 2). Of the 29 participants who received placebo in the double-blind period and progressed to open-label, 15 were re-randomized to atabecestat $5 \mathrm{mg}$ and 14 to atabecestat $25 \mathrm{mg}$. 


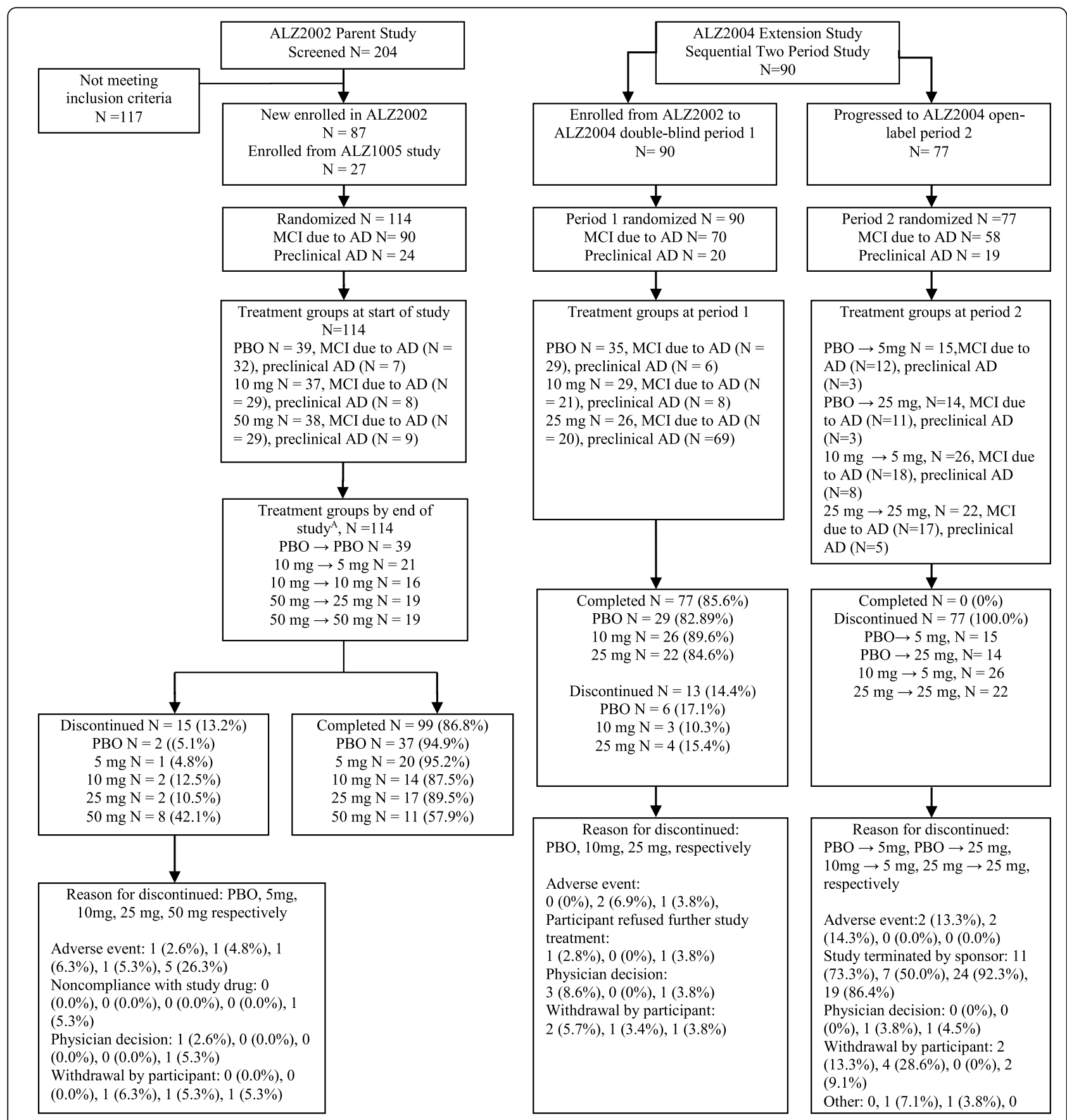

Notes: ${ }^{A}$ During the study, due to observation of elevated liver enzymes in some patients an urgent safety measure was implementation and atabecestat doses were immediately reduced in all participants which occurred when all participants had completed a minimum of 3 months of treatment and about half of the participants had completed the treatment as planned. For remaining participants on active treatment, atabecestat $10 \mathrm{mg} / \mathrm{day}$ was reduced to 5 $\mathrm{mg} /$ day, and atabecestat $50 \mathrm{mg} /$ day was reduced to $25 \mathrm{mg}$ /day.

Fig. 2 Participant dispositions for ALZ2002 parent and ALZ2004 extension studies. A During the study, due to the observation of elevated liver enzymes in some patients, an urgent safety measure was implemented and atabecestat doses were immediately reduced in all participants which occurred when all participants had completed a minimum of 3 months of treatment and about half of the participants had completed the treatment as planned. For the remaining participants on active treatment, atabecestat $10 \mathrm{mg} /$ day was reduced to $5 \mathrm{mg} /$ day, and atabecestat $50 \mathrm{mg} /$ day was reduced to $25 \mathrm{mg} /$ day 
Twenty-six participants who had received $10 \mathrm{mg}$ in the double-blind period were reduced to $5 \mathrm{mg}$ in open-label, while 22 who had received $25 \mathrm{mg}$ remained on that dosage. At the time the decision was made by the sponsor to discontinue all dosing (17 May 2018), 62 of 77 (80.5\%) participants were still receiving atabecestat in the open-label period, while the remainder had already discontinued.

\section{Fluid and imaging (VMRI) biomarker analysis}

In the ALZ2002 study, at month 6 (day 168), there was a dose-dependent mean (standard deviation $[\mathrm{SD}]$ ) percent reduction from baseline in the CSF $A \beta_{1-40}$ levels: $-42.4 \%$ [15.3] for $5 \mathrm{mg}$ (dose-reduced), $-58.7 \%$ [10.5] for $10 \mathrm{mg}$ (original dose), $-81.6 \%$ [10.8] for $25 \mathrm{mg}$ (dose-reduced), and $-83.3 \%$ [9.5] for $50 \mathrm{mg}$ (original dose) groups as shown in Fig. 3a. Similar and proportionate effects of dosage on reductions from baseline were observed for CSF $\mathrm{A} \beta_{1-37}, A \beta 1_{-38}$, and $A \beta_{1-42}$, fragments (data not shown). Plasma $A \beta_{1-40}$ levels were reduced during the treatment period with atabecestat compared with their baseline similar to CSF $A \beta_{1-40}$ (Supplementary Figure 1A). No change was observed in the placebo group. There were no significant changes on CSF A $\beta$ fragment levels on placebo.

A) Percent change in CSF A $\beta_{1-40}$ level by ALZ2002 treatment groups at end of Month 6

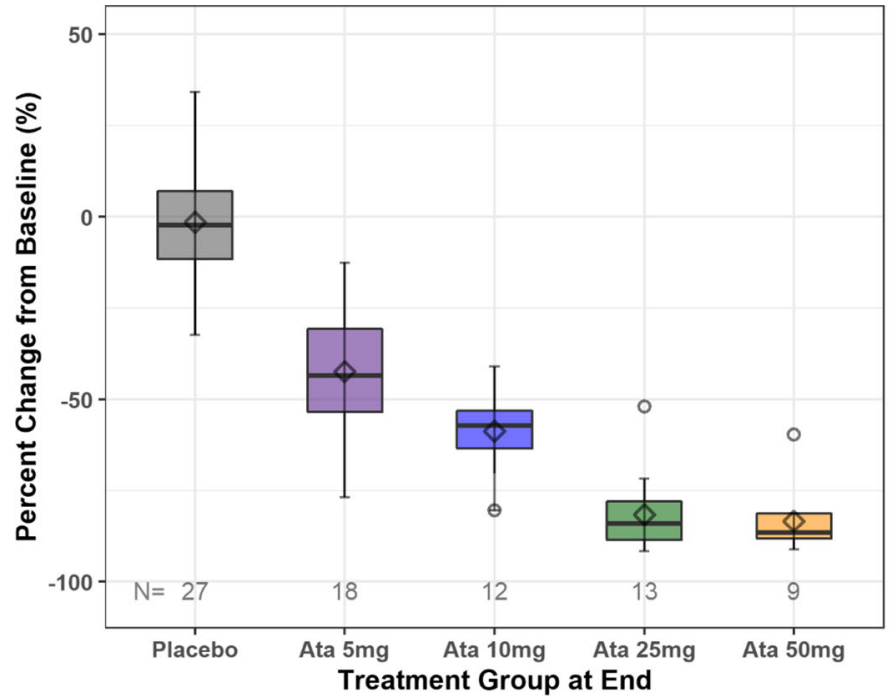

B) Percent change in CSF A $\beta_{1-40}$ level by ALZ2004 double-blind period treatment groups

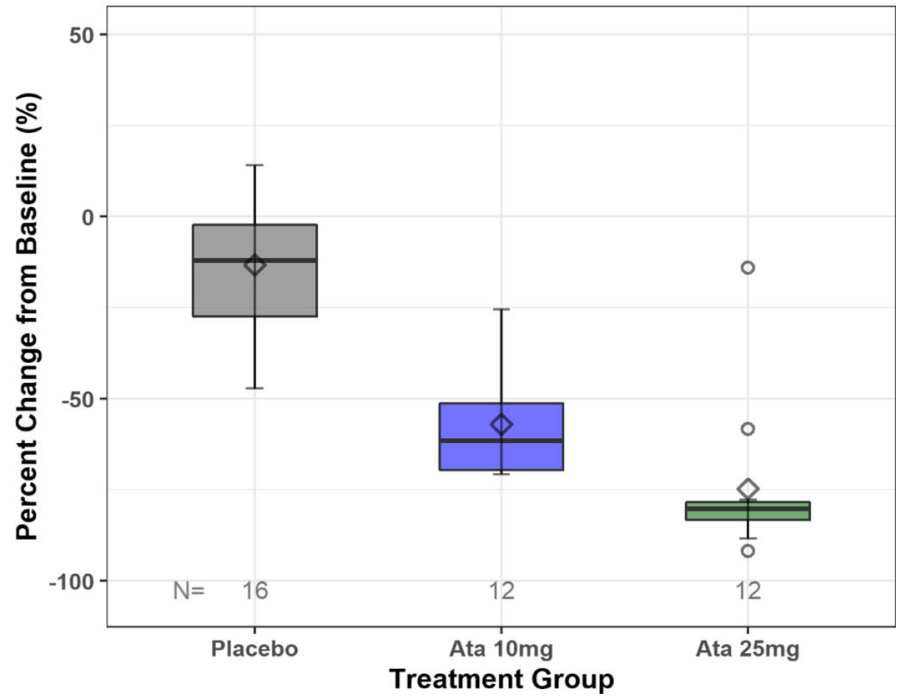

Fig. 3 a Box-whisker plots of percent change from baseline for CSF A $\beta_{1-40}$ biomarker level by final dose groups at the end of month 6 of atabecestat treatment in ALZ2002 early AD population. b Percent change from baseline time profile for CSF A $\beta_{1-40}$ levels to 52 weeks in ALZ2004 double-blind period. The line inside the box represents the median value, and the symbol represents the mean value. The outer box borders represent the lower and upper quartile (25th and 75 th percentiles of the data) 
There were no apparent differences in the change from baseline for CSF $\mathrm{A} \beta_{1-40}$ and $\mathrm{A} \beta_{1-42}$ between $A P O E \varepsilon 4$ carriers or non-carriers.

At month 6, there was a dose-dependent decrease in the CSF sAPP $\beta$ and, in contrast, a dose-dependent increase in sAPP $\alpha$ fragment levels as compared to their baseline levels, which is consistent with atabecestat mode of action in inhibition of $\beta$-secretase proteolytic cleavage of APP (Fig. 4a). No change in sAPP $\alpha$ and sAPP $\beta$ was observed in patients treated with placebo. There was no change in CSF levels of $\mathrm{t}$-tau and $\mathrm{p}$-tau ${ }_{181}$ over the 6-month treatment period across the atabecestat and placebo groups.

Box and whisker plots of change from baseline value in ALZ2002 to week 52 in ALZ2004 double-blind period are shown in Fig. 3b for CSF $A \beta_{1-40}$, in Supplementary Figure $1 B$ for plasma $A \beta_{1-40}$, and in Fig. $4 \mathrm{~b}$ for sAPP $\alpha$ and SAPP $\beta$. The magnitude of change from baseline increased with the dose administered and was similar to that of month 6 in ALZ2002. No relevant changes were observed for tau proteins.

Summary statistics of changes in the whole brain, total hippocampal, and ventricular volume during the 52-week double-blind period in ALZ2004, quantified by BSI, are presented in Table 3. Overall, as shown, numerical decreases in the whole brain and hippocampal volumes and increases in ventricular volumes from baseline were greater in participants with $\mathrm{MCI}$ due to $\mathrm{AD}$ relative to preclinical $\mathrm{AD}$, though there were no clear differences related to treatment.

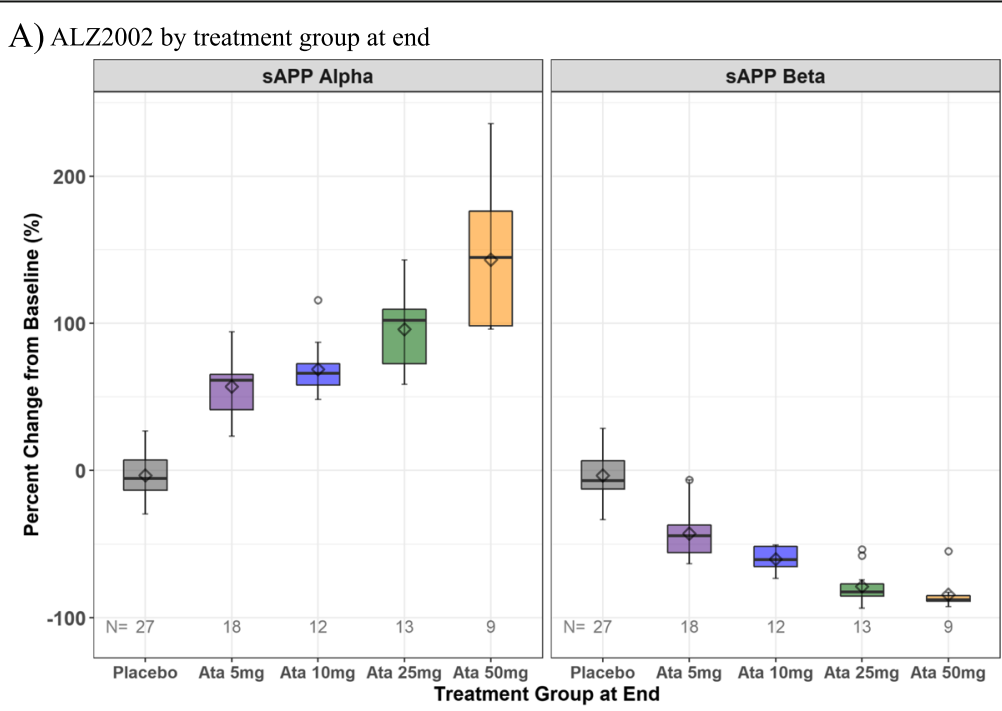

B) ALZ2004 double-blind period

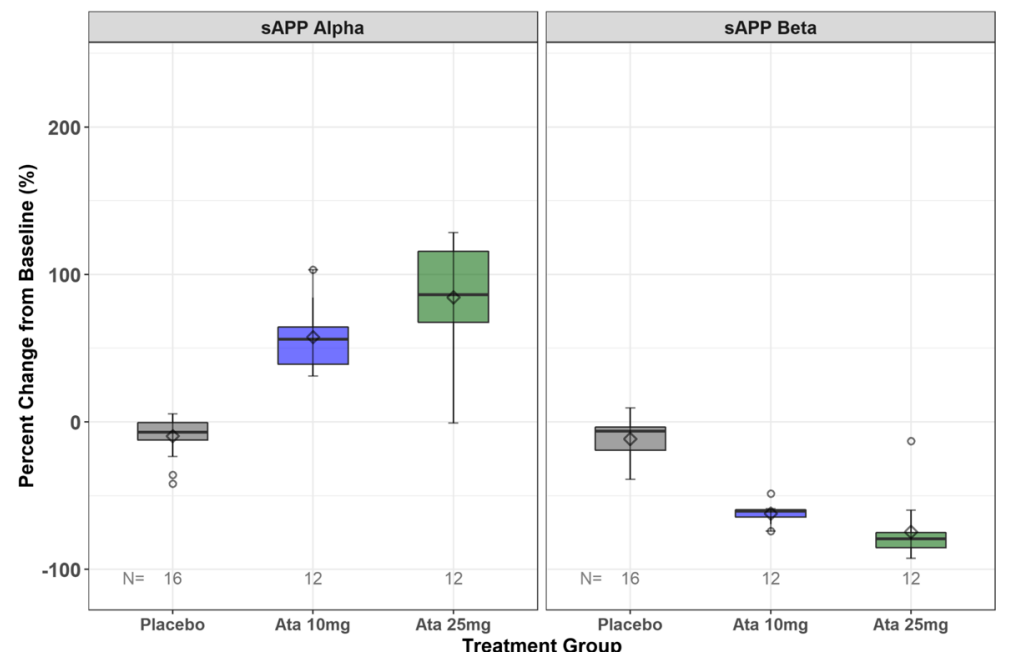

Fig. 4 a Box-whisker plots of percent change from baseline for CSF SAPPa and SAPP $\beta$ biomarkers by final dose groups at month 6 of atabecestat treatment in ALZ2002 and $\mathbf{b}$ for percent change from ALZ2002 baseline for CSF SAPPa and SAPP $\beta$ to week 52 in the ALZ2004 double-blind period 


\section{Pharmacokinetics}

The plasma PK data were described by a twocompartment model, with distribution of drug between a central (i.e., plasma) compartment and a peripheral compartment, and with linear elimination from the central compartment. Absorption was described as a linear process characterized by sequential zero- and first-order absorption from the depot compartment into the central compartment. This linear model adequately described the data and confirmed the dose-proportional PK of atabecestat in the dose range between 5 and $50 \mathrm{mg}[4,5]$. Individual estimates of $\mathrm{AUC}_{0-24 \mathrm{~h}}$ by dose are summarized in Supplementary Table S1. Participants who underwent dose reduction were included in the summary statistics with both their starting and final doses. Overall, the exposure parameters were in line with previous studies at corresponding doses $[4,5]$.

\section{Clinical scales and cognitive effects}

Mean MMSE and RBANS total scores from baseline in ALZ2002 to the end of the double-blind period in ALZ2004 are presented in Fig. 5a and b, respectively, by the treatment and diagnostic groups. ANCOVA adjusting for baseline score and diagnosis revealed that the differences in LS means relative to placebo were minimal for the MMSE (10 mg, 0.43 [90\% CI - 1.25; 2.11], $p=$ $0.6699 ; 25 \mathrm{mg}, 0.55$ [90\% CI - 1.09; 2.20], $p=0.5751$ ) but were numerically worse with atabecestat compared to placebo for total RBANS (10 mg, - 4.05 [90\% CI - 8.68; 0.59], $p=0.1499 ; 25 \mathrm{mg},-5.60$ [90\% CI $-10.47 ;-0.72$ ], $p=0.0600$ ) (Supplementary Table S2).

Mean (SD) values and standard error (SE) for change from baseline for CDR-SB, and CFI-participant and partner by the treatment group are summarized in Supplementary Table S3. There were no consistent differences related to the treatment effect. Scores on the CDR-SB worsened over time during the treatment period. No consistent change was seen for the CVLT though the interval between tests was shorter ( 9 months). Of note, CFI-partner scores did not change for preclinical $\mathrm{AD}$ but increased (worsened) for MCI due to AD, while CFI-participant scores showed slight improvement regardless of the baseline diagnosis, consistent with the observation that patients with MCI lose insight into their cognitive worsening, compared to the observation made by independent raters [14].

\section{Clinical safety \\ Adverse events other than abnormal liver enzymes}

Safety analyses included data from all randomized participants who received at least 1 dose of study drug. A summary of the incidence of treatment-emergent (TE) adverse events (AEs) by treatment groups for ALZ2002 and ALZ2004 is shown in Table 4. Overall, 81/114 (71.1\%) of the participants experienced at least $1 \mathrm{TEAE}$ in ALZ2002. The numbers of participants with at least 1 $\mathrm{AE}$, serious $\mathrm{AE}$, or $\mathrm{AE}$ leading to discontinuation were more commonly seen on the higher atabecestat dosages in ALZ2002 and the double-blind period in ALZ2004 (50 mg or $25 \mathrm{mg}$, respectively). Only 1 participant receiving placebo discontinued because of an $\mathrm{AE}$ during ALZ2004 double-blind treatment, but only participants transitioning from placebo to atabecestat discontinued because of AEs in the open-label period. There was 1 death in the study: a 77-year-old woman in the ALZ2002 atabecestat 10-mg group died on day 170 of a cholangiocarcinoma which the investigator expected to have been pre-existent, not related to study drug, and not likely to have developed within the short treatment duration.

The most common AEs (occurring in at least 2 participants and $\geq 5 \%$ in any one treatment group) are presented

Table 3 Changes in brain volumes from baseline in ALZ2002 to the end of the double-blind period in ALZ2004, by treatment group (safety analysis set)

\begin{tabular}{|c|c|c|c|c|c|c|c|c|c|}
\hline \multirow[t]{3}{*}{ Dosage } & \multirow[t]{3}{*}{ Region } & \multicolumn{4}{|c|}{ Preclinical AD } & \multicolumn{4}{|c|}{$\mathrm{MCl}$ due to $\mathrm{AD}$} \\
\hline & & \multicolumn{2}{|c|}{ Double blind week 24} & \multicolumn{2}{|c|}{ Double blind week 52} & \multicolumn{2}{|c|}{ Double blind week 24} & \multicolumn{2}{|c|}{ Double blind week 52} \\
\hline & & $n$ & Mean (SD) & $n$ & Mean (SD) & $n$ & Mean (SD) & $n$ & Mean (SD) \\
\hline \multirow[t]{3}{*}{ Placebo } & Total hippocampus & 6 & $-61.183(152.8617)$ & 4 & -192.691 (286.0535) & 23 & $-148.955(110.0055)$ & 16 & $-208.173(139.2326)$ \\
\hline & Bilateral ventricles & 6 & $1213.479(1297.2666)$ & 4 & 2384.305 (1765.8039) & 23 & $1877.688(1868.2961)$ & 16 & 2554.255 (1619.2302) \\
\hline & Whole brain & 6 & $-4513.446(6744.6900)$ & 4 & $-3966.134(6897.1749)$ & 21 & $-5202.949(5310.6112)$ & 15 & $-6398.921(6057.7712)$ \\
\hline \multirow[t]{3}{*}{$10 \mathrm{mg}$} & Total hippocampus & 8 & -130.472 (133.3899) & 4 & $-314.289(190.6022)$ & 18 & $-130.601(100.9252)$ & 16 & $-308.766(198.3581)$ \\
\hline & Bilateral ventricles & 8 & $1317.472(1089.6703)$ & 4 & 3254.365 (1326.9982) & 18 & 1294.812 (1190.6962) & 16 & $3349.908(2563.2821)$ \\
\hline & Whole brain & 8 & $-7197.703(7409.7046)$ & 4 & $-17,698.910(5463.6862)$ & 17 & $-5736.212(6275.3521)$ & 16 & $-10,815.252(9814.0704$ \\
\hline \multirow[t]{3}{*}{$25 \mathrm{mg}$} & Total hippocampus & 5 & $-12.221(92.4995)$ & 5 & $-129.273(81.0670)$ & 16 & $-122.374(86.0882)$ & 13 & $-235.946(145.2177)$ \\
\hline & Bilateral ventricles & 5 & 538.445 (965.7828) & 5 & 1999.089 (1514.6993) & 16 & 1399.116 (1085.9684) & 13 & $2853.589(1945.9111)$ \\
\hline & Whole brain & 5 & $-1144.502(7511.2280)$ & 5 & $-4524.925(6112.8815)$ & 14 & $-6634.464(5868.5297)$ & 13 & $-9624.766(8707.2218)$ \\
\hline
\end{tabular}


A) RBANS total scale (mean [SE]) over time

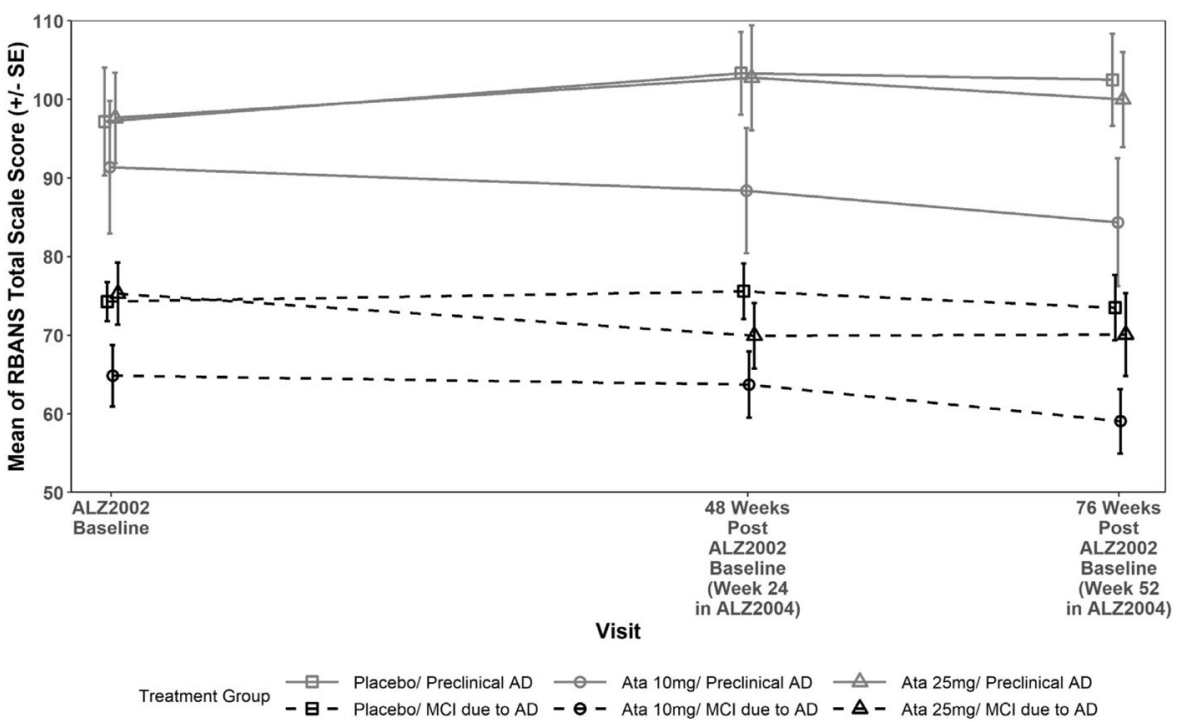

Numbers of subjects by diagnosis, treatment, and timepoint (ALZ2002 baseline, 48 weeks post baseline, and 76 weeks post baseline, respectively): Preclinical AD/ Placebo $(5,6,6), 10 \mathrm{mg}$ $(8,8,8), 25 \mathrm{mg}(6,4,5)$; MCI due to $\mathrm{AD} /$ Placebo $(28,22,24), 10 \mathrm{mg}(20,19,16), 25 \mathrm{mg}(20,17$, 12).

B) MMSE total score (mean [SE]) over time

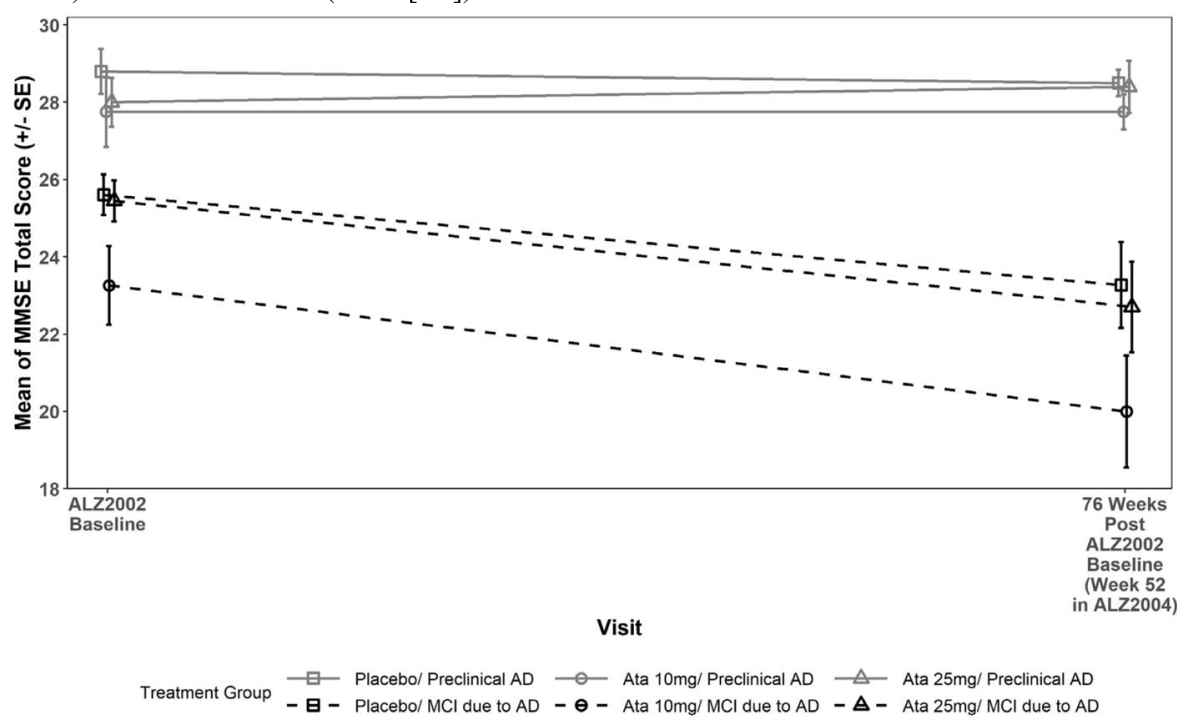

Numbers of subjects by diagnosis, treatment, and timepoint (ALZ2002 baseline and 76 weeks post baseline, respectively): Preclinical AD/ Placebo $(5,6), 10 \mathrm{mg}(8,8), 25 \mathrm{mg}(6,5)$; MCI due to $\mathrm{AD} /$ Placebo $(28,22), 10 \mathrm{mg}(19,18), 25 \mathrm{mg}(20,17)$.

Fig. 5 a RBANS total scale and b MMSE total score at baseline in ALZ2002 and at the end of the double-blind period in ALZ2004, by baseline CDR status and by treatment group

for each study period in Table 5. In ALZ2002, diarrhea was the most frequently reported TEAE associated with active treatment, occurring in 10 individuals $(8.1 \%$ of those for 10 $\mathrm{mg}$ and $18.4 \%$ of those for $50 \mathrm{mg})$. Other frequent AEs, occurring more commonly for atabecestat than placebo, included gastroesophageal reflux and influenza, 2 (5.3\%) 
Table 4 Summary of the overall treatment-mergent adverse events by the treatment group for parent study ALZ2002 and extension study ALZ2004 (safety analysis set)

\begin{tabular}{|c|c|c|c|c|c|c|c|c|c|c|c|c|c|}
\hline \multirow[t]{4}{*}{ Safety analysis set } & \multirow{2}{*}{\multicolumn{4}{|c|}{$\begin{array}{l}\text { Treatment group at start } \\
\text { ALZ2002 } \\
\text { Double-blind parent }\end{array}$}} & \multicolumn{9}{|c|}{ Treatment group in ALZ2004 } \\
\hline & & & & & \multicolumn{4}{|c|}{ Double-blind period $^{+}$} & \multicolumn{5}{|c|}{ Open-label period $^{\ddagger}$} \\
\hline & \multirow[t]{2}{*}{ Placebo } & \multirow{2}{*}{$\begin{array}{l}10 \\
\mathrm{mg}\end{array}$} & \multirow{2}{*}{$\begin{array}{l}50 \\
\mathrm{mg}\end{array}$} & \multirow[t]{2}{*}{ Total } & \multirow[t]{2}{*}{ Placebo } & \multirow{2}{*}{$\begin{array}{l}10 \\
\mathrm{mg}\end{array}$} & \multirow{2}{*}{$\begin{array}{l}25 \\
\mathrm{mg}\end{array}$} & \multirow[t]{2}{*}{ Total } & \multicolumn{5}{|c|}{ Atabecestat } \\
\hline & & & & & & & & & $\begin{array}{l}\mathrm{PBO} \rightarrow 5 \\
\mathrm{mg}\end{array}$ & $\begin{array}{l}\mathrm{PBO} \rightarrow 25 \\
\mathrm{mg}\end{array}$ & $\begin{array}{l}10 \mathrm{mg} \rightarrow \\
5 \mathrm{mg}\end{array}$ & $\begin{array}{l}25 \\
\mathrm{mg}\end{array}$ & Total \\
\hline$N$ & 39 & 37 & 38 & 114 & 35 & 29 & 26 & 90 & 15 & 14 & 26 & 22 & 77 \\
\hline Total patients with TEAEs, $n$ (\%) & $\begin{array}{l}27 \\
(69.2)\end{array}$ & $\begin{array}{l}23 \\
(62.6)\end{array}$ & $\begin{array}{l}31 \\
(81.6)\end{array}$ & $\begin{array}{l}81 \\
(71.1)\end{array}$ & $\begin{array}{l}22 \\
(62.9)\end{array}$ & $\begin{array}{l}15 \\
(51.7)\end{array}$ & $\begin{array}{l}21 \\
(80.8)\end{array}$ & $\begin{array}{l}58 \\
(64.4)\end{array}$ & $10(66.7)$ & $11(78.6)$ & $19(73.1)$ & $\begin{array}{l}16 \\
(72.7)\end{array}$ & $\begin{array}{l}56 \\
(72.7)\end{array}$ \\
\hline Serious TEAEs, $\boldsymbol{n}(\%)$ & $4(10.3)$ & $\begin{array}{l}2 \\
(5.4)\end{array}$ & $\begin{array}{l}8 \\
(21.1)\end{array}$ & $\begin{array}{l}14 \\
(12.3)\end{array}$ & $3(8.6)$ & $\begin{array}{l}4 \\
(13.8)\end{array}$ & $\begin{array}{l}4 \\
(15.4)\end{array}$ & $\begin{array}{l}11 \\
(12.2)\end{array}$ & $2(13.3)$ & $4(28.6)$ & $0(0)$ & $\begin{array}{l}1 \\
(4.5)\end{array}$ & $\begin{array}{l}7 \\
(9.1)\end{array}$ \\
\hline TEAEs leading to death, $n$ (\%) & $0(0)$ & $\begin{array}{l}1 \\
(2.7)\end{array}$ & $0(0)$ & $\begin{array}{l}1 \\
(0.9)\end{array}$ & $0(0)$ & $0(0)$ & $0(0)$ & $0(0)$ & $0(0)$ & $0(0)$ & $0(0)$ & $0(0)$ & $0(0)$ \\
\hline $\begin{array}{l}\text { Any AE leading to discontinuation } \\
\text { or withdrawal (\%) }\end{array}$ & $1(2.6)$ & $\begin{array}{l}2 \\
(5.4)\end{array}$ & $\begin{array}{l}5 \\
(13.2)\end{array}$ & $\begin{array}{l}8 \\
(7.0)\end{array}$ & $0(0)$ & $\begin{array}{l}2 \\
(6.9)\end{array}$ & $\begin{array}{l}1 \\
(3.8)\end{array}$ & $\begin{array}{l}3 \\
(3.3)\end{array}$ & $2(13.3)$ & $2(14.3)$ & $0(0)$ & $0(0)$ & $\begin{array}{l}4 \\
(5.2)\end{array}$ \\
\hline
\end{tabular}

TEAE treatment-emergent adverse events, coded using MedDRA version 21.0

${ }^{\dagger}$ Adverse events (AEs) with onset on or after the first dose of study drug in ALZ2004 through the last dose in period 1 are included. For a participant who withdrew during period 1, adverse events through the day of the last dose plus 7 days are included

${ }^{\ddagger} \mathrm{AEs}$ with onset on or after the first dose of study drug in period 2 of ALZ2004 through the day of the last dose in period 2 plus 7 days are included

participants each for $50 \mathrm{mg}$. AEs that occurred more commonly on placebo included nasopharyngitis (12.8\%), urinary tract infection $(10.3 \%)$, and headache $(10.3 \%)$, as well as vomiting, hypertension, and syncope, occurring in 7.7\% each. In the double-blind period of ALZ2004, AEs occurring more commonly on atabecestat included bronchitis $(11.5 \%)$ and nasopharyngitis $(7.7 \%)$ for the $25-\mathrm{mg}$ dosage, and falls, depressive symptoms, and malaise (6.9\% each) for the 10-mg dosage. Cataracts (17.1\%) occurred more commonly on placebo.

Retinal AEs occurred in 2 participants receiving openlabel $25 \mathrm{mg}$ (macular fibrosis) and in 3 receiving placebo (retinal degeneration, retinal detachment, and retinal exudates, respectively). There were no changes on examination by the ophthalmologist that were considered possibly related to study drug. Pigmentary changes were seen in 1 individual in the 10-mg group in ALZ2002 (skin hypopigmentation) and in 2 in the placebo group in ALZ2004 (change in hair coloration).

Eight individuals endorsed statements related to suicidal ideation on the Columbia Suicide Severity Rating Scale (though none had plan or intent) which occurred in 1 individual on placebo, 1 on placebo and later $5 \mathrm{mg}, 3$ on 5 or $10 \mathrm{mg}$, and 2 on $25 \mathrm{mg}$. Sleep disorders have been reported for other BACE1 inhibitors in other trials [15]. Sleep-related complaints in this study included insomnia (1 patient on placebo, 1 on $10 \mathrm{mg}$, and 2 on $25 \mathrm{mg}$ ), nightmares (1 on placebo, 1 on $25 \mathrm{mg}$, and transitioning from placebo to $5 \mathrm{mg}$ [2] or $25 \mathrm{mg}$ [1]), parasomnias (1 on $10 \mathrm{mg}$ ), and rapid eye movement sleep abnormalities (1 on $25 \mathrm{mg}$ ).

\section{AEs related to elevated liver enzymes}

Hepatic-related AEs were reported only in the atabecestat treatment groups and not in the placebo group in ALZ2002 and in the double-blind period in ALZ2004. The reported AE terms included increased alanine aminotransferase (ALT), increased aspartate aminotransferase (AST), increased transaminases, increased hepatic enzymes, and increased gamma-glutamyl transferase (GGT). Five individuals, including 4 for $50 \mathrm{mg}$ and 1 for $10 \mathrm{mg}$, had these reported as serious AEs during doubleblind treatment in ALZ2002 and in the double-blind period in ALZ2004, and 2 had these reported as serious AEs transitioning from placebo to $5 \mathrm{mg}$ or to $25 \mathrm{mg}$ in open-label period. These individuals all discontinued treatment because of these AEs.

Treatment-emergent increases in ALT or AST ( $>1$ to $<2 \times \mathrm{ULN}, 2$ to $<3 \times \mathrm{ULN}$, and $>3 \mathrm{X} \mathrm{ULN}$ ) are presented in Table 6 for starting dosage in ALZ2002 and for the double-blind and open-label periods in ALZ2004. Mild increases $(<3 \times \mathrm{ULN})$ were seen more commonly on atabecestat than on placebo. Only 1 participant had an increase in ALT > 3× ULN while receiving placebo, due to acute cholecystitis. A total of 12 participants had an increase in ALT $>3 \times$ ULN while receiving atabecestat, including 5 in ALZ2002, 3 in the double-blind period of ALZ2004, and 4 in participants transitioning from placebo to $5 \mathrm{mg}$ ( 1 case) or to $25 \mathrm{mg}$ ( 3 cases).

All cases of ALT or AST $>3 \times$ ULN occurred within the first year of exposure, including 7 between days 33 and 168, 4 between days 259 and 343, and 1 at day 201, 32 days after the last dose. In 3 cases, transaminases normalized with continued treatment; in 8, it resolved with discontinuation, 
Table 5 Incidence of the most frequent (> 5\%) adverse events occurring in the ALZ2002 and the ALZ2004 double-blind and openlabel periods

\begin{tabular}{|c|c|c|c|c|c|}
\hline Body system/preferred term & Treatment group & & & & \\
\hline ALZ2002 (double-blind) & Placebo & & Ata $10 \mathrm{mg}$ & Ata $50 \mathrm{mg}$ & Total \\
\hline$N$ & 39 & & 37 & 38 & 114 \\
\hline Diarrhea & $2(5.1 \%)$ & & $3(8.1 \%)$ & $7(18.4 \%)$ & $12(10.5 \%)$ \\
\hline Nasopharyngitis & $5(12.8 \%)$ & & $3(8.1 \%)$ & $3(7.9 \%)$ & $11(9.6 \%)$ \\
\hline Headache & $4(10.3 \%)$ & & $2(5.4 \%)$ & $2(5.3 \%)$ & $8(7.0 \%)$ \\
\hline Back pain & $2(5.1 \%)$ & & $2(5.4 \%)$ & $2(5.3 \%)$ & $6(5.3 \%)$ \\
\hline Hypertension & $3(7.7 \%)$ & & $2(5.4 \%)$ & $1(2.6 \%)$ & $6(5.3 \%)$ \\
\hline Transaminases increased & 0 & & $2(5.4 \%)$ & $3(7.9 \%)$ & $5(4.4 \%)$ \\
\hline Urinary tract infection & $4(10.3 \%)$ & & $1(2.7 \%)$ & 0 & $5(4.4 \%)$ \\
\hline Influenza & $1(2.6 \%)$ & & 0 & $2(5.3 \%)$ & $3(2.6 \%)$ \\
\hline Syncope & $3(7.7 \%)$ & & 0 & 0 & $3(2.6 \%)$ \\
\hline Vomiting & $3(7.7 \%)$ & & 0 & 0 & $2(2.6 \%)$ \\
\hline Cataract & $2(5.1 \%)$ & & 0 & 0 & $2(1.8 \%)$ \\
\hline Gastroesophageal reflux disease & 0 & & 0 & $2(5.3 \%)$ & $2(1.8 \%)$ \\
\hline Alanine aminotransferase increased & 0 & & $2(5.4 \%)$ & $3(7.9 \%)$ & $5(4.4 \%)$ \\
\hline Vitamin $B_{12}$ decreased & $2(5.1 \%)$ & & 0 & 0 & $2(1.8 \%)$ \\
\hline ALZ2004, double-blind period & Placebo & & Ata $10 \mathrm{mg}$ & Ata $25 \mathrm{mg}$ & Total \\
\hline$N$ & 35 & & 29 & 26 & 90 \\
\hline Cataract & $6(17.1 \%)$ & & 0 & $2(7.7 \%)$ & $8(8.9 \%)$ \\
\hline Nasopharyngitis & $2(5.7 \%)$ & & $2(6.9 \%)$ & $2(7.7 \%)$ & $6(6.7 \%)$ \\
\hline Bronchitis & $1(2.9 \%)$ & & $1(3.4 \%)$ & $3(11.5 \%)$ & $5(5.6 \%)$ \\
\hline Fall & $2(5.7 \%)$ & & $2(6.9 \%)$ & 0 & $4(4.4 \%)$ \\
\hline Diarrhea & $1(2.9 \%)$ & & $1(3.4 \%)$ & $1(3.8 \%)$ & $3(3.3 \%)$ \\
\hline Depressive symptom & 0 & & $2(6.9 \%)$ & 0 & $2(2.2 \%)$ \\
\hline Insomnia & 0 & & 0 & $2(7.7 \%)$ & $2(2.2)$ \\
\hline Malaise & 0 & & $2(6.9 \%)$ & 0 & $2(2.2 \%)$ \\
\hline ALZ2004 open-label period & Placebo/Ata $5 \mathrm{mg}$ & Placebo/Ata $25 \mathrm{mg}$ & Ata $5 \mathrm{mg}$ & Ata $25 \mathrm{mg}$ & Total \\
\hline$N$ & 15 & 14 & 28 & 22 & 77 \\
\hline Nasopharyngitis & $1(6.7 \%)$ & $3(21.4 \%)$ & $3(11.5 \%)$ & $1(4.5 \%)$ & $8(10.4 \%)$ \\
\hline Headache & 0 & $2(14.3 \%)$ & $3(11.5 \%)$ & $1(4.5 \%)$ & $6(7.8 \%)$ \\
\hline Back pain & $1(6.7 \%)$ & 0 & 0 & $3(13.6 \%)$ & $4(5.2 \%)$ \\
\hline Pneumonia & 0 & $2(14.3 \%)$ & $2(7.7 \%)$ & 0 & $4(5.2 \%)$ \\
\hline Cataract & 0 & 0 & $2(7.7 \%)$ & $1(4.5 \%)$ & $3(3.9 \%)$ \\
\hline Macular fibrosis & 0 & 0 & 0 & $2(9.1 \%)$ & $2(2.6 \%)$ \\
\hline Depression & $2(13.3 \%)$ & 0 & 0 & $1(4.5 \%)$ & $3(3.9 \%)$ \\
\hline Nightmare & $2(13.3 \%)$ & $1(7.1 \%)$ & 0 & 0 & $3(3.9 \%)$ \\
\hline Insomnia & 0 & 0 & 0 & $2(9.1 \%)$ & $2(2.6 \%)$ \\
\hline Confusional state & 0 & $1(7.1 \%)$ & 0 & 0 & $1(1.3 \%)$ \\
\hline Delirium & $1(6.7 \%)$ & 0 & 0 & 0 & $1(1.3 \%)$ \\
\hline Psychotic disorder & 0 & $1(7.1 \%)$ & 0 & 0 & $1(1.3 \%)$ \\
\hline
\end{tabular}

and in 1 with abnormal ALT at baseline (2.7× ULN), it remained mildly elevated after discontinuation. All individuals were asymptomatic, except a 78-year-old man receiving $50 \mathrm{mg}$ who presented on day 33 with a "flu-like" illness and a cholestatic pattern of abnormalities (ALT 5.4× ULN, alkaline phosphatase 3.6 ULN, and GGT $14.1 \times$ ULN). This resolved by day 56 following discontinuation of atabecestat, but recurred on day 89 , in the setting of fever and other constitutional symptoms, a markedly elevated erythrocyte sedimentation rate, and temporal arteritis on biopsy. This 
Table 6 Incidence of treatment-emergent abnormal value of ALT or AST

\begin{tabular}{|c|c|c|c|c|c|c|c|c|c|c|}
\hline \multirow{3}{*}{$\begin{array}{l}\text { Study } \\
\text { Period } \\
\text { Treatment group }\end{array}$} & \multirow{2}{*}{\multicolumn{3}{|c|}{$\frac{\text { ALZ2002 }}{\text { Double-blind }}$}} & \multicolumn{7}{|l|}{ ALZ2004 } \\
\hline & & & & \multicolumn{3}{|c|}{ Double-blind } & \multicolumn{4}{|l|}{ Open-label } \\
\hline & Placebo & Ata $10 \mathrm{mg}$ & Ata $50 \mathrm{mg}$ & Placebo & Ata $10 \mathrm{mg}$ & Ata $25 \mathrm{mg}$ & Placebo/5 mg & Placebo/25 mg & $5 \mathrm{mg}$ & $25 \mathrm{mg}$ \\
\hline AST or ALT, $n$ & 39 & 34 & 37 & 35 & 29 & 26 & 15 & 14 & 26 & 22 \\
\hline $\begin{array}{l}>\text { ULN to } \leq 2 \times \\
\text { ULN, } n(\%)\end{array}$ & 0 & $5(14.7)$ & $8(21.6)$ & $2(5.7)$ & $1(3.4)$ & $7(26.9)$ & $4(26.7)$ & $2(14.3)$ & $3(11.5)$ & $7(31.8)$ \\
\hline $\begin{array}{l}>2 \times \text { ULN to } \leq 3 \times \\
\text { ULN, } n(\%)\end{array}$ & 0 & $2(5.9)$ & $1(2.7)$ & 0 & $2(6.9)$ & $1(3.8)$ & 0 & $2(14.3)$ & 0 & 0 \\
\hline > $3 \times$ ULN, $n$ (\%) & 1 (2.6) & $2(5.9)$ & $2(5.4)$ & 0 & $2(6.9)$ & 1 (3.8) & $1(6.7)$ & $3(21.4)$ & 0 & 0 \\
\hline
\end{tabular}

ALT alanine aminotransferase, AST aspartate aminotransferase, ULN upper limit of normal

For double-blind period 1, baseline is defined as the pre-dose baseline value from the preceding parent ALZ2002 study. For open-label period 2, baseline is

defined as the last value taken on or before the day of the first dose of study drug in the open-label period

resolved on a course of corticosteroids. A cholestatic pattern of liver enzymes is known to occur in approximately one-third of cases of temporal arteritis [16]. In all other cases, the pattern was hepatocellular, with ALT > AST. The highest elevations of ALT occurred in 1 participant receiving $50 \mathrm{mg}$ (15.7× ULN) and in 1 receiving $25 \mathrm{mg}$ (13.9x ULN). No abnormalities meeting "Hy's law" criteria (ALT or AST $>3 \times$ ULN and total bilirubin $>2 \times$ ULN) were observed.

\section{Discussion}

The effect of atabecestat on lowering CSF A $\beta$ levels was dose-proportional and was maintained over a longer term in the extension study, confirming its pharmacodynamic effects of reducing the production of $A \beta$ by central inhibition of BACE1 cleavage of APP. The A $\beta$ reduction was consistent with previous findings from the ALZ1005 study which showed mean percent reduction from baseline in CSF $A \beta_{1-40}$ of $67.3 \%$ and $89.9 \%$ for 10 $\mathrm{mg}$ and $50 \mathrm{mg}$, respectively, after 4 weeks of treatment [5]. This finding was not associated with statistically significant change in cognition or clinical scales, though a trend for a worsening of RBANS total score in the 10$\mathrm{mg}$ and 25-mg groups relative to placebo was observed. There were no consistent changes in volumetric MRI related to treatment.

In this study, treatment-emergent increases in serum ALT, surpassing $3 \times$ ULN, were seen in 12 of 104 (11.5\%) individuals exposed to atabecestat (including 8 of 75 in double-blind treatment and 4 of 29 participants transitioning from placebo to atabecestat). Though the frequency was similar for the higher and lower doses of atabecestat, there was a limited experience in those receiving $5 \mathrm{mg}$ as the only dosage (only 14 participants). These AEs were nearly all asymptomatic and resolved either spontaneously or after discontinuation of treatment.

In a separate phase $2 \mathrm{~b} / 3$ double-blind placebocontrolled study of atabecestat in preclinical AD (EARLY trial, ALZ2003), conducted concurrently with ALZ2004, mean decreases from baseline in PACC and RBANS scores (worsening) for participants on atabecestat treatment were statistically significant for the $25-\mathrm{mg}$ group versus placebo at 6 and 12 months and 3 months, respectively [17]. The clinical significance of cognitive decline in atabecestat treatment groups relative to placebo is unclear, but similar results favoring placebo were reported with other BACE1 inhibitors such as verubecestat in phase 3 trials for prodromal $A D$ and mild-to-moderate AD [15, 18]. Knopman [19] noted that these observations may suggest that lowering BACE1 activity could result in adverse effects on normal synaptic functions possibly due to excessive BACE1 inhibition and only a low degree of inhibition may be needed to decrease $A \beta$ production. The cognitive changes described for several BACE inhibitors may be due to effects on other BACE substrates given diverse physiological function of BACE1 besides APP processing. While the relevance of BACE inhibitor's nonselective blockage of BACE2, a close homolog of BACE1, remains unknown, it may theoretically lead to some AEs $[20,21]$. Hence, the amount of $A \beta$ reduction may not correlate with the effect on cognitive worsening and as such may warrant further investigation.

The EARLY trial had an active data safety monitoring board ensuring participant safety in the clinical trials. Because of the hepatic enzyme elevations observed in ALZ2002 as well as in EARLY, rigorous hepatic safety case management and hepatic safety algorithms had been implemented. With accumulation in the number and severity of hepatic enzyme elevations, the sponsor decided on 18 May 2018 to stop treatment in all atabecestat clinical trials.

Late phase clinical trials of other BACE1 inhibitors were recently terminated early or stopped for futility due to the lack of efficacy or for safety reasons, including studies of verubecestat (Merck, NJ, USA) in patients with mild-tomoderate AD (EPOCH study, NCT01739348) [15] and with amnestic MCI (APECS study, NCT 01953601) [18], 
and studies of lanabecestat (AstraZeneca, UK, and Eli Lilly IN, USA) in patients with $\mathrm{MCI}$ due to $\mathrm{AD}$ or mild $\mathrm{AD}$ dementia (AMARANTH NCT 02245737, DAYBREAK NCT02783573), [22]. Two phase 3 trials of elenbecestat (Biogen, MA, USA, and Eisai) in early AD spectrum (MISSION AD1 NCT02956486, MISSION AD2 NCT03036280) were expected to report findings by 2021 but were recently terminated for safety concerns. Although evidence of liver toxicity in patients does not appear to be a BACE inhibitor class effect, there were previous reports that phase 2 trials of LY-2886721 (Eli Lilly, IN, USA) were stopped due to abnormal liver biochemistry values flagged in 4 out of 45 patients during routine safety monitoring. Liver abnormalities were considered to be an off-target effect of that compound [23].

Interpretation of some of the analyses was limited by early termination of the ALZ2004 extension study and the small sample size, particularly the limited number of participants with normal cognition.

\section{Conclusions}

In the 6-month ALZ2002 parent study, an atabecestat 50mg dose was generally less well tolerated than lower doses with a higher frequency of participants discontinuing treatment early. Hepatic transaminase elevations were observed in the atabecestat treatment groups but not in the placebo group, resulting in dose reduction and discontinuation of the 50-mg dose. In addition, safety measures for monitoring hepatic function tests were implemented.

In the longer term extension study, some participants on active treatment in ALZ2004 double-blind and openlabel periods exhibited transaminase elevations, including markedly abnormal ALT elevations accompanied by elevations in AST and in some cases by elevations in GGT. The elevations occurred between 3 and 12 months of treatment, and all resolved after discontinuation of study treatment except for one with a baseline elevation in transaminases. A trend for decreases from baseline in RBANS scores with $10 \mathrm{mg}$ and $25 \mathrm{mg}$ atabecestat treatment was observed in the extension study, indicating worsening of cognitive performance consistent with reports of other BACE inhibitors.

Given the frequency of hepatic enzyme elevations and concern for managing participant safety outside the structure of a clinical trial, dosing of atabecestat in ALZ2004 and EARLY was halted. The EARLY data, as well as data from multiple other BACE inhibitors, confirmed the trends for worsened cognition seen for the RBANS in the ALZ2002 and ALZ2004 studies. While BACE inhibition remains an intriguing mechanism to slow $\mathrm{AD}$ progression, a better understanding of BACE substrates is important prior to additional human studies.

\section{Supplementary information}

Supplementary information accompanies this paper at https://doi.org/10. 1186/s13195-020-00614-5.

Additional file 1. Supplementary information on the Methods.

Additional file 2. Supplementary Tables and Figures.

Additional file 3. Supplementary Material.

\section{Abbreviations}

APP: Amyloid precursor protein; BACE1: $\beta$-Secretase1 enzyme; A $\beta$ : Amyloid beta; AD: Alzheimer's disease; CSF: Cerebrospinal fluid; MCl: Mild cognitive impairment; OL: Open-label; sAPP: Soluble amyloid precursor protein; ttau: Total tau; p-tau 181 : Phosphorylated tau; CDR: Clinical Dementia Rating Scale; BMI: Body mass index; MRI: Magnetic resonance imaging; DSM: Diagnostic and Statistical Manual of Mental Disorders; PET: Positron emission tomography; ALT: Alanine aminotransferase; AST: Aspartate aminotransferase; GGT: Gamma-glutamyl transferase; ULN: Upper limit of normal; CDR-SB: CDR-sum of boxes; MMSE: Mini-Mental State Examination; RBANS: Repeatable Battery for the Assessment of Neuropsychological Status; CVLT-II: California Verbal Learning Test-second edition; CFI: Cognitive Function Index; ECL: Electrochemiluminescence; MSD: Meso Scale Discovery; PK: Pharmacokinetic; $\mathrm{AUC}_{0-24}$ h: Area under the plasma concentration-time curve at steady state; CL/F: Estimate of oral clearance; AEs: Adverse events; SOC: System Organ Class; TEAEs: Treatment-emergent adverse events; SAE: Serious adverse event; ARIA-E: Amyloid-related imaging abnormalities with edema or effusion; ARIA-H: ARIA with hemosiderin; C-SSRS: Columbia Suicide Severity Rating Scale; ANCOVA: Analysis of covariance;

VMRI: Volumetric MRI; LS: Least squares; SD: Standard deviation; SE: Standard error

\section{Acknowledgements}

The authors are most grateful to the study participants for their contributions and the investigational staff for the medical care. The authors acknowledge Kouji Ohno, PhD (Research Laboratory for Development, SHIONOGI \& CO., LTD., Osaka Japan), and Yoshiyuki Matsuo, PhD (Global Project Management Dept., SHIONOGI \& CO., LTD., Osaka, Japan), for the data review and discussions. The authors acknowledge Bradford Challis, PhD (Janssen Research \& Development, LLC), for additional editorial support. The authors also thank Marianne Borgers, Luc Gys, Daan Van Glabbeek, and Katja De Waepenaert for their contributions to the development of sAPP assays and QPS Netherlands B.V. for CSF and plasma A $\beta$ analyses.

\section{Authors' contributions}

Drs. Streffer and Novak were the study medical officers and participated in the study design and conduct of the trial, data analysis plan, interpretation, and review of the manuscript. Dr. Engelborghs was the principal investigator for the European trial, involved in patient recruitment, study operation, study management, data collection, interpretation, and review and finalization of the study report. Drs. Timmers, Henley, Brashear, Tesseur, Tritsmans, and Van Nueten were responsible for the study design, data interpretation, and review of the manuscript. Drs. Brashear, Novak, and Bogert were responsible for safety data review committee and its charter. Dr. Russu was responsible for the PK data interpretation and modeling and simulation. Dr. Tesseur was responsible for the bioanalyses of pharmacodynamic biomarkers data. Jennifer Bogert and Luc Janssens were the project clinical biostatisticians and responsible for data collection and analyses. All authors participated in the interpretation of the data and drafting of the manuscript. All authors met ICMJE criteria, and all those who fulfilled those criteria are listed as authors. All authors had access to the study data, provided direction and comments on the manuscript, made the final decision about where to publish these data, and approved the final draft and submission to this journal.

\section{Funding}

This research was funded by Janssen Research \& Development, a division of Janssen Pharmaceutica NV, Beerse, Belgium, and by a Transformational Medical Research Grant (IWT 120834) from Flanders Innovation \&

Entrepreneurship (VLAIO), Belgium. The funding sponsor was responsible for the study design, data collection, data analysis, and data interpretation, and provided support for writing of the manuscript. The corresponding author 
had full access to all data in the studies and had final responsibility for the decision to submit for publication.

\section{Availability of data and materials}

The datasets analyzed during the present study are not publicly available, but they are available at http://yoda.yale.edu/johnson-johnson. Requests for access to the study data can be submitted through this independent site for review.

\section{Ethics approval and consent to participate}

The study protocol and amendments were approved by the appropriate Independent Ethics Committee/Institutional Review Board. Written informed consent was obtained from all participants before their participation. All study procedures followed were in accordance with the current $\mathrm{ICH}$ guidelines on Good Clinical Practice (GCP), applicable regulatory and country-specific requirements, and the principals of the Declaration of Helsinki.

\section{Consent for publication}

Not applicable.

\section{Competing interests}

All authors, except Dr. Engelborghs, report personal fees (current or former employment) from Janssen Research \& Development, a Division of Janssen Pharmaceutica NV, Beerse, Belgium, or Janssen Research \& Development, LLC, Raritan, NJ, USA, or Janssen Research and Development LLC, Titusville, NJ, USA, and all own stock/stock options in the company. Dr. Streffer is a former employee of Janssen Pharmaceutica NV and is currently affiliated with UCB Biopharma, Belgium, and with a research advisory role at Reference Center for Biological Markers of Dementia (BIODEM), Institute Born-Bunge, University of Antwerp, Antwerp, Belgium, and collects no consulting fees and receives no research funding. Dr. Tesseur is a former employee of Janssen Pharmaceutica NV and is currently affiliated with UCB Biopharma, Belgium, and has nothing to disclose. Dr. Tritsmans is a former employee of Janssen Pharmaceutica NV and reports no disclosures.

Dr. Engelborghs is employed at the Department of Biomedical Sciences, University of Antwerp, 2610 Antwerp, and at the Department of Neurology and Center for Neurosciences, UZ Brussel, and Vrije Universiteit Brussel (VUB), Brussels, Belgium, and reports research funding from Janssen Pharmaceutica NV and ADx Neurosciences (paid to institution).

\section{Author details}

${ }^{1} J a n s s e n$ Research and Development LLC, 1125 Trenton-Harbourton Rd, Titusville, NJ 08560, USA. ${ }^{2}$ Janssen Research and Development, a Division of Janssen Pharmaceutica NV, Beerse, Belgium. ${ }^{3}$ Reference Center for Biological Markers of Dementia (BIODEM), Institute Born-Bunge, University of Antwerp, Antwerp, Belgium. ${ }^{4}$ Present address: UCB Biopharma SPRL, Chemin du Foriest, B-1420 Braine-l'Alleud, Belgium. ${ }^{5}$ Janssen Research and Development LLC, Raritan, NJ, USA. ${ }^{6}$ Department of Neurology and Center for Neurosciences, UZ Brussel and Vrije Universiteit Brussel (VUB), Brussels, Belgium.

Received: 4 February 2020 Accepted: 2 April 2020 Published online: 14 May 2020

\section{References}

1. Hardy JA, Higgins GA. Alzheimer's disease: the amyloid cascade hypothesis. Science. 1992;256:184-5.

2. Karran E, Mercken M, De Strooper B. The amyloid cascade hypothesis for Alzheimer's disease: an appraisal for the development of therapeutics. Nat Rev Drug Discov. 2011;10:698-712.

3. Jonsson T, Atwal JK, Steinberg S, Snaedal J, Jonsson PV, Bjornsson S, et al. A mutation in APP protects against Alzheimer's disease and age-related cognitive decline. Nature. 2012:488:96-9.

4. Timmers M, Van Broeck B, Ramael S, Slemmon J, De Waepenaert K, Russu A, Bogert JM, Stieltjes H, Shaw LM, Engelborghs S, Moechars D, Mercken M, Liu E, Sinha V, Kemp J, Van Nueten L, Tritsmans L, Streffer JR. Profiling the dynamics of CSF and plasma A reduction after treatment with JNJ54861911, a potent oral BACE inhibitor. Alzheimers Dement. 2016;2:202-12.

5. Timmers $M$, Streffer JR, Russu A, Tominaga $Y$, Shimizu H, Shiraishi A, et al. Pharmacodynamics of atabecestat (JNJ-54861911), an oral BACE1 inhibitor in patients with early Alzheimer's disease: randomized, double-blind, placebo-controlled study. Alzheimers Res Ther. 2018;10:85.

6. Hansson O, Zetterberg H, Buchhave P, Londos E, Blennow K, Minthon L. Association between CSF biomarkers and incipient Alzheimer's disease in patients with mild cognitive impairment: a follow-up study. Lancet Neurol. 2006:5:228-34.

7. Palmqvist S, Zetterberg H, Blennow K, Vestberg S, Andreasson U, Brooks DJ, et al. Accuracy of brain amyloid detection in clinical practice using cerebrospinal fluid beta-amyloid 42: a cross-validation study against amyloid positron emission tomography. JAMA Neurol. 2014;71:1282-9.

8. FDA US. Guidance for industry drug-induced liver injury: premarketing clinical evaluation. Silver Spring: US FDA; 2009. https://www.fda.gov/ regulatory-information/search-fda-guidance-documents/drug-induced-liverinjury-premarketing-clinical-evaluation. Accessed 23 July 2019.

9. Struyfs H, Van Broeck B, Timmers M, Fransen E, Sleegers K, Van Broeckhoven C, et al. Diagnostic accuracy of cerebrospinal fluid amyloid-beta isoforms for early and differential dementia diagnosis. J Alzheimers Dis. 2015;45:813-22.

10. Van Broeck B, Timmers M, Ramael S, Bogert J, Shaw LM, Mercken M, Slemmon R, Van Nueten L, Engelborghs S, Streffer JR. Impact of frequent cerebrospinal fluid sampling on $A \beta$ levels: systematic approach to elucidate influencing factors. Alzheimer's Research \& Therapy. 2016;8:21-30.

11. Prados F, Cardoso MJ, Leung KK, Cash DM, Modat M, Fox NC, et al. Measuring brain atrophy with a generalized formulation of the boundary shift integral. Neurobiol Aging. 2015:36(Suppl 1):S81-90.

12. Rochin L, Hurbain I, Serneels L, Fort C, Watt B, Leblanc P, et al. BACE2 processes PMEL to form the melanosome amyloid matrix in pigment cells. Proc Natl Acad Sci U S A. 2013;110:10658-63.

13. Brashear HR, Ketter N, Bogert J, Di J, Salloway SP, Sperling R. Clinical evaluation of amyloid-related imaging abnormalities in bapineuzumab phase III studies. J Alzheimers Dis. 2018:66:1409-24.

14. Vannini P, Amariglio R, Hanseeuw B, Johnson KA, McLaren DG, Chhatwal J, et al. Memory self-awareness in the preclinical and prodromal stages of Alzheimer's disease. Neuropsychologia. 2017;99:343-9.

15. Egan MF, Kost J, Tariot PN, Aisen PS, Cummings JL, Vellas B, et al. Randomized trial of verubecestat for mild-to-moderate Alzheimer's disease. N Engl J Med. 2018;378:1691-703.

16. Selmi C, De Santis M, Gershwin ME. Liver involvement in subjects with rheumatic disease. Arthritis Res Ther. 2011;13:226.

17. Henley D, Raghavan N, Sperling R, Aisen P, Raman R, Romano G. Preliminary results of a trial of atabecestat in preclinical Alzheimer's disease. N Engl J Med. 2019:380:1483-5.

18. Egan MF, Kost J, Voss T, Mukai Y, Aisen PS, Cummings JL, et al. Randomized trial of verubecestat for prodromal Alzheimer's disease. N Engl J Med. 2019; 380:1408-20.

19. Knopman DS. Lowering of amyloid-beta by beta-secretase inhibitors - some informative failures. N Engl J Med. 2019;380:1476-8.

20. Barao S, Moechars D, Lichtenthaler SF, De Strooper B. BACE1 physiological functions may limit its use as therapeutic target for Alzheimer's disease. Trends Neurosci. 2016;39:158-69.

21. Ben Halima S, Mishra S, Raja KMP, Willem M, Baici A, Simons K, et al. Specific inhibition of beta-secretase processing of the Alzheimer disease amyloid precursor protein. Cell Rep. 2016;14:2127-41.

22. Piton M, Hirtz C, Desmetz C, Milhau J, Lajoix AD, Bennys K, et al. Alzheimer's disease: advances in drug development. J Alzheimers Dis. 2018;65:3-13.

23. Yan R. Stepping closer to treating Alzheimer's disease patients with BACE1 inhibitor drugs. Transl Neurodegener. 2016;5:13.

\section{Publisher's Note}

Springer Nature remains neutral with regard to jurisdictional claims in published maps and institutional affiliations. 